\title{
Using an incentive spirometer reduces pulmonary complications in patients with traumatic rib fractures: a randomized controlled trial
}

Shao-Kai Sum', Ya-Chuan Peng ${ }^{2}$, Shun-Ying Yin ${ }^{1}$, Pin-Fu Huang ${ }^{1}$, Yao-Chang Wang ${ }^{1}$, Tzu-Ping Chen ${ }^{1}$, Heng-Hsin Tung ${ }^{3}$ and Chi-Hsiao Yeh ${ }^{1,4^{*}}$ (D)

\begin{abstract}
Background: An incentive spirometer (IS) is a mechanical device that promotes lung expansion. It is commonly used to prevent postoperative lung atelectasis and decrease pulmonary complications after cardiac, lung, or abdominal surgery. This study explored its effect on lung function and pulmonary complication rates in patients with rib fractures.

Methods: Between June 2014 and May 2017, 50 adult patients with traumatic rib fractures were prospectively investigated. Patients who were unconscious, had a history of chronic obstructive pulmonary disease or asthma, or an Injury Severity Score (ISS) $\geq 16$ were excluded. Patients were randomly divided into a study group $(n=24)$, who underwent IS therapy, and a control group $(n=26)$. All patients received the same analgesic protocol. Chest X-rays and pulmonary function tests (PFTs) were performed on the 5th and 7th days after trauma.
\end{abstract}

Results: The groups were considered demographically homogeneous. The mean age was 55.2 years and $68 \%$ were male. Mean pretreatment ISSs and mean number of ribs fractured were not significantly different (8.23 vs. 8.08 and 4 vs. 4, respectively). Of 50 patients, 28 (56\%) developed pulmonary complications, which were more prevalent in the control group (80.7\% vs. 29.2\%; $p=0.001)$. Altogether, 25 patients had delayed hemothorax, which was more prevalent in the control group $(69.2 \%$ vs. $29.2 \% ; p=0.005)$. Two patients in the control group developed atelectasis, one patient developed pneumothorax, and five patients required thoracostomy. PFT results showed decreased forced vital capacity (FVC) and forced expiratory volume in $1 \mathrm{~s}\left(\mathrm{FEV}_{1}\right)$ in the control group. Comparing pre- and posttreatment FVC and $\mathrm{FEV}_{1}$, the study group had significantly greater improvements $(p<0.001)$.

Conclusions: In conclusion, the use of an IS reduced pulmonary complications and improved PFT results in patients with rib fractures. The IS is a cost-effective device for patients with rib fractures and its use has clinical benefits without harmful effects.

Trial registration: ClinicalTrials.gov, NCT04006587. Registered on 3 July 2019.

Keywords: Incentive spirometer, Rib fracture, Pulmonary complications, Forced vital capacity, Forced expiratory volume

\footnotetext{
* Correspondence: yehccl@cgmh.org.tw

${ }^{1}$ Department of Thoracic and Cardiovascular Surgery, Chang Gung Memorial

Hospital, 222 Mai-Chin Road, Keelung 204, Taiwan, Republic of China

${ }^{4}$ School of Medicine, Chang Gung University, Tao-Yuan, Taiwan

Full list of author information is available at the end of the article
}

(c) The Author(s). 2019 Open Access This article is distributed under the terms of the Creative Commons Attribution 4.0 International License (http://creativecommons.org/licenses/by/4.0/), which permits unrestricted use, distribution, and reproduction in any medium, provided you give appropriate credit to the original author(s) and the source, provide a link to the Creative Commons license, and indicate if changes were made. The Creative Commons Public Domain Dedication waiver (http://creativecommons.org/publicdomain/zero/1.0/) applies to the data made available in this article, unless otherwise stated. 


\section{Introduction}

Chest trauma patients account for around $10-15 \%$ of all traffic accident victims. In the United States, 400,000 patients are admitted to hospital annually due to chest trauma [1]. Chest trauma is the second highest cause of mortality due to traffic accidents, accounting for about $25 \%$ of deaths, which is only slightly lower than for deaths due to head injuries [2]. Chest trauma may involve a variety of organs, including the heart, great vessels, lungs, trachea, and the esophageal or chest wall. Rib fracture is one of the most common injuries, accounting for about $61-90 \%$ of injuries [3]. Multiple complications can follow rib fracture, including pneumothorax, hemothorax, lung contusion, flail chest, atelectasis, respiratory failure, and even death. Atelectasis is the most common complication [2-8]. The mortality rate related to rib fracture has been reported to be $10-12 \%[9,10]$ and is dependent on the severity of the intra- and extra- thoracic injuries, age, heart disease, diabetes mellitus, pneumonia, and the number of fractured ribs [11-14]. Rib fracture patients commonly complain about chest pain, which is caused by damaged lung hygiene, obstruction of the lower airway, and subsequent atelectasis and hypoventilation. Hypoxemia, pneumonia, respiratory failure, and other morbidities may cause lengthy hospital stays and mortality $[2-4,6,15]$. Rib fracture patients do not usually require surgical intervention. However, admission for pain control and further observation are required to maintain lung hygiene and prevent further complications.

An incentive spirometer (IS) is a mechanical device that helps lung expansion. It is commonly used to prevent postoperative lung atelectasis and decreased pulmonary complications after cardiac, lung, or abdominal surgery. It can increase the maximal inspiration capacity and lung compliance, improve oxygenation, and maintain the patency of lower airways to prevent and treat atelectasis [12, 16-22]. This study explored the effects of using an IS on lung function and pulmonary complication rate in rib fracture patients.

\section{Methods}

After institutional review board approval (Chang Gung Medical Foundation, reference 103-0421A3; ClinicalTrials.gov Identifier: NCT04006587), we recruited adult patients ( $>18$ years old) seen at our institution between June 2014 until May 2017 with traumatic rib fractures. Written inform consent was obtained from all participants. For inclusion, a patient had to have at least one rib fracture as detected by a chest X-ray or computed tomography scan.

A total of 50 patients were enrolled into this study. We excluded patients who were unconscious, had a history of chronic obstructive pulmonary disease or asthma, or an Injury Severity Score (ISS) $\geq 16$. Patients were randomly allocated into two groups using sealed envelopes [23]: a study group $(n=24)$ who were advised to use the IS and a control group $(n=26)$ who did not use the IS (Fig. 1). A flow-oriented Tri-flow (model TB-93100; Besmed Health Business Corporation, New Taipei City, Taiwan) was used. These devices are easy to use and the results are clearly visible, with the three floating balls indicating inspiratory flows of 600,900 , and $1200 \mathrm{ml} / \mathrm{s}$. All patients were managed with the same oral analgesic protocol. A chest X-ray was obtained on the 1st and 5th days of admission by a radiologist. A pulmonary function test (PFT; Microspiro HI298, Chest Corporation, Tokyo, Japan) was performed on the 2nd and 7th days of hospitalization by a pulmonologist. The results were defined as the pre-test and post-test, respectively. Each patient's forced vital capacity (FVC) and forced expiratory volume in $1 \mathrm{~s}\left(\mathrm{FEV}_{1}\right)$ were recorded. The predictive values (\%FVC predictive and $\% \mathrm{FEV}_{1}$ predictive) for each patient were individualized according to weight, height, sex, and age. According to Ruppel [24] normal values are $\mathrm{FVC}>80 \%, \mathrm{FEV}_{1}>75 \%, \mathrm{FEV}_{1} / \mathrm{FVC} \mathrm{( \% )}>75 \%$, and flow rate $>60 \%$. A numeric rating scale (NRS) was used to define the severity of chest pain on the 1st and 5th days of admission.

In the study group, patients were shown how to use the IS in a seated or semi-seated position. They were instructed to maintain a sustained maximal inspiration for $3-5 \mathrm{~s}$ before exhalation, ten times per hour, for at least 8 hours a day [25]. The primary outcome for this group was pulmonary complication rate, including complications such as atelectasis, pneumonia, hemothorax, and pneumothorax. The secondary outcomes were lung function test measurements (including $\% \mathrm{FVC}$ and $\% \mathrm{FEV}_{1}$ ), length of hospital stay, and chest pain as assessed by the NRS. The discharge criteria were stable vital signs, absence of pulmonary complications (such as atelectasis, pneumonia, pneumothorax, and hemothorax), and acceptable pain (NRS $<4)$.

\section{Statistical analysis}

Categorical variables, such as sex, smoking status, rib fracture site, number of ribs fractured, trauma mechanism, associated injuries, comorbidities, and use of anticoagulants or anti-platelets, were summarized with counts and percentages. Continuous variables, such as age, height, weight, body mass index (BMI), and ISS were summarized with means and standard deviation. An analysis of covariance (ANCOVA) was used to evaluate pre- and post-test lung function in the two groups. Between-group comparisons of the outcomes after IS use, including pulmonary complications, PFT results, length of hospitalization, and pain scores, were analyzed using an independent $t$-test, a chi-squared test, and a 


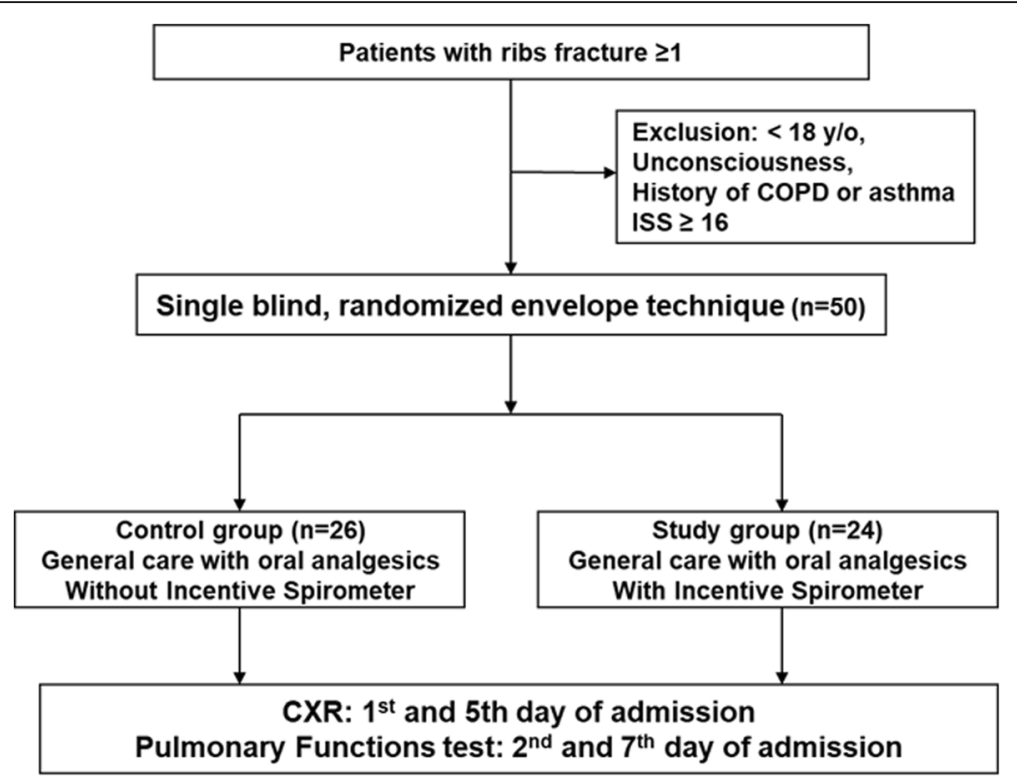

Fig. 1 Study flow chart. COPD chronic obstructive pulmonary disease, CXR chest X-ray, ISS Injury Severity Score, y/o years old

paired $t$-test. All $p$ values were two-sided, and $p<0.05$ was considered statistically significant. The sample size was determined with $\mathrm{G}^{*}$ Power (version 3.1.9.4, Universität Kiel, Germany), which found that 25 subjects per group were needed to provide $80 \%$ power to detect the results as significant at $\alpha=5 \%$ [26]. All statistical analyses were performed using SPSS version 20 (IBM, Armonk, NY, USA).

\section{Results}

\section{Demographic information}

Between June 2014 and May 2017, 50 patients with traumatic rib fractures who were admitted to our institution were recruited into this study after providing written inform consent. The patients were prospectively and randomly divided into two groups using sealed envelopes. There were no differences in age or gender between the groups. Patients in the study group $(n=24)$ were advised to use the IS and the other group was not (control group; $n=26)$. Their average age was $55.2 \pm 14.5$ years (range 18 to 88 years) and 34 patients $(68 \%)$ were male. The mean number of ribs fractured was $3.94 \pm 2.05$ (study group $3.79 \pm 2.21$; control group $4.08 \pm 1.94 ; p=$ $0.341)$. The number of patients with three or more fractured ribs was 39 (78\%) (control group 21 [80.8\%]; study group 18 [75\%]; not significant). The mean ISS was $8.16 \pm 3.76$ (study group $8.08 \pm 3.78$; control group $8.23 \pm 3.81 ; p=0.894)$. The site of rib fracture did not differ between the groups, and only four patients (8\%) had bilateral rib fractures, one in the study group and three in the control group. The most common mechanism of trauma was a motorcycle accident (about 50\%), and the second most common was a fall from at least 3 m (about 24\%). Associated injuries included eight patients with clavicle fractures, five patients with scapular fractures, four patients with bone fractures of the extremities, one patient with head injuries, and one patient with a liver laceration. Only five patients were using anti-platelets or anti-coagulants before the trauma, three in the study group and two in the control group. There were no statistically significant differences in smoking history, comorbidities, trauma mechanism, or BMI between the two groups (Table 1).

\section{Pulmonary function test}

There were no statistically significant between-group differences for $\% \mathrm{FVC}(p=.371)$ or $\mathrm{FEV}_{1}(p=.717)$ in the pre-test. In the control group, the pre-test \%FVC was $70.44 \pm 16.99 \%$ and the post-test $\% \mathrm{FVC}$ was $65.58 \pm$ $16.36 \%$, representing a $4.86 \pm 10.92 \%$ decrease. In the study group, the pre-test \%FVC was $59.05 \pm 15.34 \%$ and the post-test $\% \mathrm{FVC}$ was $77.72 \% \pm 13.28$, representing an $18.65 \pm 17.77 \%$ improvement $(p<0.001)$ (Table 2$)$. There was no change in \%FEV1 $(-5.28 \pm 11.95 \%)$ between the pre-test and post-test in the control group and a significant $(19.49 \pm 17.50 \%)$ improvement in the study group between the pre-test and post-test $(p<0.001)$.

\section{Pulmonary complications}

Altogether, 28 patients developed pulmonary complications, including 21 patients $(75 \%)$ in the control group and 7 patients $(25 \%)$ in the study group $(p<0.001)$. The most common complication was hemothorax (25 patients, $89.2 \%)$, including 18 patients (72\%) in the control group. Five of these required a tube thoracostomy. In 
Table 1 Patient demographics

\begin{tabular}{|c|c|c|c|c|}
\hline & $\begin{array}{l}\text { Whole } \\
\text { cohort } \\
n=50(\%)\end{array}$ & $\begin{array}{l}\text { Control } \\
\text { group } \\
n=26(\%)\end{array}$ & $\begin{array}{l}\text { Study } \\
\text { group } \\
n=24(\%)\end{array}$ & $\begin{array}{l}p \\
\text { value }\end{array}$ \\
\hline Age (years) & $55.2 \pm 14.5$ & $54.5 \pm 15.2$ & $56.0 \pm 13.9$ & 0.904 \\
\hline Sex (male, \%) & $34(68 \%)$ & 17 (65.4\%) & 17 (70.8\%) & 0.680 \\
\hline Height (cm) & $164.0 \pm 7.9$ & $163.0 \pm 7.4$ & $165.0 \pm 8.5$ & 0.216 \\
\hline Weight (kg) & $69.0 \pm 12.0$ & $70.9 \pm 10.9$ & $66.8 \pm 12.9$ & 0.281 \\
\hline $\mathrm{BMI}\left(\mathrm{kg} / \mathrm{m}^{2}\right)$ & $25.6 \pm 4.2$ & $26.7 \pm 4.7$ & $24.4 \pm 3.2$ & 0.493 \\
\hline ISS & $8.2 \pm 3.8$ & $8.2 \pm 3.8$ & $8.1 \pm 3.8$ & 0.894 \\
\hline \multicolumn{5}{|l|}{$\begin{array}{l}\text { Initial blood } \\
\text { laboratory data }\end{array}$} \\
\hline $\begin{array}{l}\text { White blood } \\
\text { cell }\left(10^{3} / \mathrm{uL}\right)\end{array}$ & & $15.3 \pm 5.4$ & $12.3 \pm 5.0$ & 0.466 \\
\hline $\begin{array}{l}\text { Hemoglobin } \\
(\mathrm{g} / \mathrm{dL})\end{array}$ & & $12.6 \pm 2.9$ & $13.7 \pm 1.7$ & 0.500 \\
\hline Hematocrit (\%) & & $37.1 \pm 7.5$ & $39.9 \pm 4.3$ & 0.466 \\
\hline $\begin{array}{l}\text { Platelet count } \\
\left(10^{3} / \mathrm{uL}\right)\end{array}$ & & $225.4 \pm 63.6$ & $\begin{array}{l}209.7 \pm \\
44.2\end{array}$ & 0.518 \\
\hline $\begin{array}{l}\text { Prothrombin } \\
\text { time/INR }\end{array}$ & & $0.99 \pm 0.04$ & $1.00 \pm 0.04$ & 0.593 \\
\hline APTT ratio & & $0.95 \pm 0.07$ & $0.92 \pm 0.07$ & 0.549 \\
\hline $\begin{array}{l}\text { Blood urea } \\
\text { nitrogen (mg/dL) }\end{array}$ & & $19.2 \pm 7.7$ & $9.0 \pm 4.2$ & 0.473 \\
\hline Creatinine (mg/dL) & & $0.89 \pm 0.16$ & $0.97 \pm 0.31$ & 0.343 \\
\hline AST (U/L) & & $34.0 \pm 9.5$ & $27.3 \pm 11.4$ & 0.306 \\
\hline Sodium (mmol/L) & & $137.2 \pm 3.5$ & $138.9 \pm 2.3$ & 0.463 \\
\hline $\begin{array}{l}\text { Potassium } \\
(\mathrm{mmol} / \mathrm{L})\end{array}$ & & $3.9 \pm 0.9$ & $3.8 \pm 0.5$ & 0.406 \\
\hline Smoking status & & & & 0.247 \\
\hline Non-smoker & $31(62 \%)$ & $14(53.8 \%)$ & 17 (70.8\%) & \\
\hline History of smoking & $3(6 \%)$ & $1(3.8 \%)$ & $2(8.3 \%)$ & \\
\hline Current smoker & $16(32 \%)$ & $11(42.3 \%)$ & $5(20.8 \%)$ & \\
\hline Injury site & & & & 0.425 \\
\hline Left & $25(50 \%)$ & $11(42.3 \%)$ & $14(58.3 \%)$ & \\
\hline Right & $21(42 \%)$ & $12(46.2 \%)$ & $9(37.5 \%)$ & \\
\hline Bilateral & $4(8 \%)$ & $3(11.5 \%)$ & $1(4.2 \%)$ & \\
\hline $\begin{array}{l}\text { Number of ribs } \\
\text { fractured }\end{array}$ & $3.94 \pm 2.05$ & $4.08 \pm 1.94$ & $3.79 \pm 2.21$ & 0.341 \\
\hline$<3$ & $11(22 \%)$ & $5(19.2 \%)$ & $6(25 \%)$ & 0.623 \\
\hline$\geq 3$ & $39(78 \%)$ & $21(80.8 \%)$ & $18(75 \%)$ & 0.623 \\
\hline Trauma mechanism & & & & 0.243 \\
\hline Car accident & $6(12 \%)$ & $4(15.4 \%)$ & $2(8.3 \%)$ & \\
\hline $\begin{array}{l}\text { Motorcycle } \\
\text { accident }\end{array}$ & $25(50 \%)$ & $10(38.5 \%)$ & $15(62.5 \%)$ & \\
\hline Pedestrian & $2(4 \%)$ & 0 & $2(8.3 \%)$ & \\
\hline Fall $<3 \mathrm{~m}$ & $12(24 \%)$ & $8(30.8 \%)$ & $4(16.7 \%)$ & \\
\hline Fall $>3 \mathrm{~m}$ & $2(4 \%)$ & $2(7.7 \%)$ & 0 & \\
\hline Work accident & $2(4 \%)$ & $1(3.8 \%)$ & $1(4.2 \%)$ & \\
\hline Fighting & $1(2 \%)$ & $1(3.8 \%)$ & 0 & \\
\hline
\end{tabular}

Table 1 Patient demographics (Continued)

\begin{tabular}{lllll}
\hline & $\begin{array}{l}\text { Whole } \\
\text { cohort } \\
n=50(\%)\end{array}$ & $\begin{array}{l}\text { Control } \\
\text { group } \\
n=26(\%)\end{array}$ & $\begin{array}{l}\text { Study } \\
\text { group } \\
n=24(\%)\end{array}$ & $\begin{array}{l}p \\
\text { value }\end{array}$ \\
\hline Associated injuries & & & & \\
$\quad \begin{array}{l}\text { Fracture of } \\
\text { extremity }\end{array}$ & $4(8 \%)$ & $2(7.7 \%)$ & $2(8.3 \%)$ & 0.933 \\
Head & $1(2 \%)$ & $1(3.8 \%)$ & 0 & 0.332 \\
$\quad$ Liver laceration & $1(2 \%)$ & $1(3.8 \%)$ & 0 & 0.332 \\
$\begin{array}{l}\text { Scapular fracture } \\
\text { Clavicle fracture }\end{array}$ & $5(10 \%)$ & $2(7.7 \%)$ & $3(12.5 \%)$ & 0.571 \\
$\begin{array}{l}\text { Diabetes mellitus } \\
\text { Hypertension }\end{array}$ & $12(24 \%)$ & $2(7.7 \%)$ & $6(25 \%)$ & 0.095 \\
$\begin{array}{l}\text { Heart disease } \\
\text { Kidney disease }\end{array}$ & $5(17(34 \%)$ & $7(26.9 \%)$ & $10(41.7 \%)$ & 0.272 \\
$\begin{array}{l}\text { Anti-platelet/ } \\
\text { Coagulant use } \\
\text { before trauma }\end{array}$ & $5(10 \%)$ & $2(7.7 \%)$ & $3(12.5 \%)$ & 0.571 \\
\hline
\end{tabular}

APTT activated partial thromboplastin time, AST aspartate aminotransferase, $B M I$ body mass index, INR international normalized ratio, ISS Injury Severity Score

comparison, seven patients (28\%) in the study group developed hemothorax $(p=0.005)$ (Table 3). One patient in the control group developed pneumothorax, but none in the study group, and two patients developed atelectasis. There were no cases of pneumonia in either group.

\section{Length of hospitalization and pain score}

The mean length of hospitalization was $9.98 \pm 3.93$ days, and there was no significant difference between the groups (Table 4). The mean score on the NRS for chest pain was 4.1 points and pain severity decreased between the 1st and 5th days of admission. The analgesic protocol achieved similar results in both groups.

\section{Discussion}

Our results prove that IS use in patients with traumatic rib fractures can reduce pulmonary complications, including atelectasis and hemothorax, and further interventions. Moreover, IS use by patients with a traumatic

Table 2 ANCOVA of pulmonary function test

\begin{tabular}{llll}
\hline Covariant & Control group $(n=26)$ & Study group $(n=24)$ & $p$ value \\
\hline \%FEV 1 pre-test & $71.96 \pm 16.33$ & $60.48 \pm 16.65$ & .717 \\
\%FEV 1 post-test & $66.66 \pm 16.97$ & $79.97 \pm 13.04$ & $.003^{*}$ \\
\%FEV ${ }_{1}$ difference & $-5.28 \pm 11.95$ & $19.49 \pm 17.50$ & $<.001^{*}$ \\
\%FVC pre-test & $70.44 \pm 16.99$ & $59.05 \pm 15.34$ & .371 \\
\%FVC post-test & $65.58 \pm 16.36$ & $77.72 \pm 13.28$ & $.006^{*}$ \\
\%FVC difference & $-4.85 \pm 10.92$ & $18.65 \pm 17.77$ & $<.001^{*}$ \\
\hline
\end{tabular}

ANCOVA analysis of covariance, $F E V_{1}$ forced expiratory value in $1 \mathrm{~s}, F V C$ forced vital capacity ${ }^{*} p<0.05$ 
Table 3 Pulmonary complications

\begin{tabular}{|c|c|c|c|c|c|}
\hline & $\begin{array}{l}\text { Whole } \\
\text { cohort }\end{array}$ & Control & Study & $t$-test & $p$ value \\
\hline & $N=50$ & $n=26$ & $n=24$ & & \\
\hline $\begin{array}{l}\text { Pulmonary } \\
\text { complications }\end{array}$ & & & & 11.538 & $.001^{*}$ \\
\hline No & $22(44 \%)$ & $5(19.2 \%)$ & 17 (70.8\%) & & \\
\hline Yes & $28(56 \%)$ & $21(80.7 \%)$ & $7(29.2 \%)$ & & \\
\hline Pneumothorax & & & & 0.942 & .332 \\
\hline No & 49 (98\%) & 25 (96.2\%) & 24 (100\%) & & \\
\hline Yes & $1(2 \%)$ & 1 (3.8\%) & 0 & & \\
\hline Hemothorax & & & & 8.013 & $.005^{*}$ \\
\hline No & 25 (50\%) & $8(30.8 \%)$ & 17 (70.8\%) & & \\
\hline Yes & $25(50 \%)$ & $18(69.2 \%)$ & 7 (29.2\%) & & \\
\hline \multicolumn{6}{|l|}{ Pneumonia } \\
\hline No & $50(100 \%)$ & $26(100 \%)$ & $24(100 \%)$ & & \\
\hline Yes & 0 & 0 & 0 & & \\
\hline Atelectasis & & & & 1.923 & .166 \\
\hline No & 48 (96\%) & $24(92.3 \%)$ & 24 (100\%) & & \\
\hline Yes & $2(4 \%)$ & $2(7.7 \%)$ & 0 & & \\
\hline $\begin{array}{l}\text { Tube } \\
\text { thoracostomy }\end{array}$ & $5(10 \%)$ & $5(19.2 \%)$ & 0 & 5.128 & .051 \\
\hline
\end{tabular}

rib fracture can improve their pulmonary function, as assessed by PFT, especially \%FVC and $\% \mathrm{FEV}_{1}$. Using an IS device did not prolong the length of hospitalization nor increase the severity of chest pain.

\section{Population of chest trauma}

Our study population was predominantly male (68\%). A study by Byun and Kim [27] conducted between 2002 and 2008 on 418 rib fracture patients also had more male patients (327 [78\%] males and 91 [22\%] females). Shulzhenko et al. [28] reviewed a database of 67,659 patients aged $\geq 65$ years with traumatic rib fractures. There were 36,966 (54.6\%) male patients and 30,715 (45.4\%) female patients. Ekpe and Eyo [29] reported that $84.4 \%$ of patients with traumatic rib fractures were male (54 of 64 patients). In 2017, accidents were the sixth leading cause of death in Taiwan. There were 6965 fatalities, and 73\% of the deaths were male [30]. Our study is consistent with these studies and proves that the high predominance of males in trauma studies may be because males often occupy high-risk jobs, such as in the transportation industry, and are more likely to ride motorcycles.

\section{Severity of chest trauma}

The ISS standardizes the severity of traumatic injury, and a higher score may indicate higher mortality and morbidity. The lowest ISS in our study was 2 and the highest was 14 , with a mean of $8.16 \pm 3.17$. Byun and Kim [27] found a mean ISS of 15.27 in 418 patients with rib fractures, with mortality and pneumonia rates that correlated with ISS $(p<0.001)$. In the database of 67,659 patients aged $\geq 65$ years with traumatic rib fractures studied by Shulzhenko et al. [28], 24,128 people (35.6\%) had an ISS of 1-9 in, 19,388 people (28.6\%) an ISS of 10-16, and 22,825 people $(33.7 \%)$ an ISS of $17-75$. Butts et al. [31] reported the ISSs for 99 patients with rib fractures. The lowest score was 9 and the highest was 14, with a mean of 10. In our patients, the ISSs were much lower due to our exclusion criteria (ISS > 16), and we excluded post-trauma complications, such as pneumonia, which may be due to other types of severe trauma. Patient comorbidities, such as hyperglycemia and cardiovascular disease, can affect the post-trauma complication rate and mortality, and in particular, underlying pulmonary disease can increase the pneumonia rate after rib fracture [32]. We excluded patients who had chronic obstructive airway disease, asthma, or other pulmonary diseases at the beginning of the study.

\section{Beneficial effect of IS on surgical patients}

The benefit of using an IS is that it forces the patient to take long deep breaths and hold them for seconds, thereby reducing breathing effort, decreasing the activity of accessory muscles, promoting diaphragmatic breathing, opening up the alveoli, improving tidal volume and basal ventilation, and consequently, encouraging the cleaning out of secretions. The preventive effect of IS on postoperative pulmonary complications has been proved

Table 4 Length of stay and numeric rating scale of pain

\begin{tabular}{|c|c|c|c|c|c|}
\hline & $\begin{array}{l}\text { Whole cohort } \\
N=50\end{array}$ & $\begin{array}{l}\text { Control } \\
n=26\end{array}$ & $\begin{array}{l}\text { Study } \\
n=24\end{array}$ & $x^{2} / t$ & $p$ value \\
\hline Length of stay (days) & $9.98 \pm 3.93$ & $9.92 \pm 4.10$ & $10.04 \pm 3.82$ & 0.313 & .578 \\
\hline \multicolumn{6}{|l|}{ NRS } \\
\hline 1st day & $4.34 \pm 1.41$ & $4.23 \pm 1.45$ & $4.46 \pm 1.38$ & 0.567 & .361 \\
\hline 2nd day & $3.26 \pm 1.38$ & $3.38 \pm 1.70$ & $3.13 \pm 0.95$ & 0.660 & .663 \\
\hline 5th day & $2.87 \pm 1.33$ & $3.00 \pm 1.48$ & $2.73 \pm 1.17$ & 0.686 & .634 \\
\hline
\end{tabular}

NRS numeric rating scale 
by many studies. Renault et al. [33] randomly assigned 36 patients who underwent coronary artery bypass surgery into two groups: a deep breathing exercise group $(n=18)$ and an IS group $(n=18)$. Although there was no significant difference in $\mathrm{FVC}$ or $\mathrm{FEV}_{1}$ between the two groups, there were improvements in pulmonary function in the IS group. Alaparthi et al. [34] randomly assigned 260 patients who had undergone laparoscopic abdominal surgery into four groups, including a diaphragmatic breathing exercise group, a volume-flow IS group, and a control group. All patients had improved FVC and FEV 1 on the second day after surgery, but the improvements in the flow IS group were more significant. Rollin et al. [35] carried out a retrospective study with 84 patients who had undergone laparoscopic donor nephrectomy. Five patients in the general care group developed pneumonia after surgery, but there were no cases of pneumonia in the IS group. Koo and Hwang [36] assigned 63 patients who had undergone upper abdominal surgery into a control group $(n=32)$ and an IS group $(n=32)$. Five patients (16.1\%) in the control group developed pulmonary complications compared to none in the IS group $(p=0.18)$.

\section{Beneficial effects of IS on patients with chest trauma}

The other beneficial effect of IS is on $\mathrm{O}_{2}$ saturation of post-traumatic rib fracture patients. Moon et al. [37] investigated 25 patients with rib fractures who used an IS after their admission to hospital. Their PFT results and $\mathrm{O}_{2}$ saturation levels improved day by day. In our study, 28 patients $(56 \%)$ developed pulmonary complications after admission, 21 (75\%) of whom were in the control group $(p<0.001)$. There were no cases of atelectasis in the IS group but two patients in the control group developed atelectasis $(p=0.166)$. There were no cases of pneumonia in our cohort. A total of 25 patients developed delayed hemothorax, 18 (72\%) of whom were in the control group $(p=0.005)$. Five of these patients underwent a tube thoracostomy. A prospective study of minor blunt chest trauma by Misthos et al. found that delayed hemothorax was most frequently diagnosed in patients on the seventh day after blunt rib fracture, which is the main cause of hemothorax [38]. Whether IS can help to restore the alignment of fractured ribs and decrease cases of delayed hemothorax, as seen in our results, needs further study.

Despite the small sample size of our study, the results of this prospective randomized study prove that posttraumatic IS can effectively reduce post-traumatic pulmonary complications, including atelectasis, delayed hemothorax, and the need for a tube thoracotomy, in patients with traumatic rib fractures. Currently, the evidence-based therapeutic interventions for a rib fracture include only multimodal pain management, pulmonary hygiene, and operative stabilization [39]. The importance of pulmonary hygiene, the most commonly written order for patients with rib fractures, is a belief that is deeply held by practitioners. However, there is little evidence to show that this intervention for patients with rib fractures improves outcomes [40]. Our results provide direct evidence for the therapeutic effects of IS, besides the improvement in oxygen saturation, in preventing post-traumatic pulmonary complications in patients with rib fractures.

\section{Limitations}

This study had several limitations. First, our relatively small sample size may not be representative of the population of rib fracture patients in Taiwan. We included only patients who were admitted to hospital and it is likely that patients who are not admitted also suffer from delayed pulmonary complications. This may limit the generalizability of our results to wider populations. In future, we may consider extending the inclusion criteria to encompass outpatients and patients attending an emergency department. Second, we performed pulmonary function testing only within 1 week of trauma, so the outcomes reported are relatively short term. Further studies on long-term outcomes and on training on IS compliance after discharge will help to further our knowledge of the benefits of IS. Third, our interventional procedures are challenging to blind, but the effort would be worthwhile by avoiding bias. However, blinding was reported to be successful in only a few interventional studies $(13 / 63 ; 21 \%)[41]$.

\section{Conclusion}

In conclusion, IS use reduced pulmonary complications, including atelectasis and hemothorax, and further interventions, such as a tube thoracostomy, in patients with rib fractures. Furthermore, the PFT results in patients who used an IS showed significant improvements in $\% \mathrm{FVC}$ and $\% \mathrm{FEV}_{1}$. The IS device does not extend the length of hospitalization or increase the severity of chest pain. These devices are easy to use and they have clinical benefits for patients with rib fractures without harmful effects.

\section{Abbreviations}

ANCOVA: Analysis of covariance; BMI: Body mass index; CXR: Chest X-ray; FEV ${ }_{1}$ : Forced expiratory volume in $1 \mathrm{~s}$; FVC: Forced vital capacity; IS: Incentive spirometer; ISS: Injury Severity Score; NRS: Numeric rating scale;

PFT: Pulmonary function test

\section{Acknowledgements}

None.

Authors' contributions

SKS, YCP, SYY, HHT, and CHY were responsible for conception and design. TPC and SYY provided administrative support. YCW, PFH, TPC, and SYY supplied study materials and recruited participants. SKS and YCP collected 
the data. SKS, YCP, and HHT were responsible for the analysis and interpretation of the data. SKS, YCP, SYY, and CHY wrote this manuscript. All authors read and approved the final version of the manuscript.

\section{Funding}

This work was supported by grants CMRPG 2E0221 (to YCP) and CMRPG 2F0212 (to CHY) from Chang Gung Memorial Hospital, Keelung.

\section{Availability of data and materials}

All data generated and analysed during this study are included in this published article.

\section{Ethics approval and consent to participate}

This trails has been approved by the relevant institutional review board (1030421A3; ClinicalTrials.gov identifier NCT04006587). We recruited adult patients (>18 years old) seen at our institution between June 2014 and May 2017 with traumatic rib fractures. Written inform consent was obtained from all participants.

\section{Consent for publication}

Not applicable.

\section{Competing interests}

The authors declare that they have no competing interests.

\section{Author details}

'Department of Thoracic and Cardiovascular Surgery, Chang Gung Memorial Hospital, 222 Mai-Chin Road, Keelung 204, Taiwan, Republic of China. ${ }^{2}$ Department of Nursing, Chang Gung Memorial Hospital, Keelung, Taiwan. ${ }^{3}$ School of Nursing, National Taipei University of Nursing and Health Science, Taipei, Taiwan. ${ }^{4}$ School of Medicine, Chang Gung University, Tao-Yuan, Taiwan.

Received: 9 August 2019 Accepted: 28 November 2019 Published online: 30 December 2019

\section{References}

1. Karadayi S, Nadir A, Sahin E, Celik B, Arslan S, Kaptanoglu M. An analysis of 214 cases of rib fractures. Clinics (Sao Paulo). 2011:66:449-51.

2. Stitzel JD, Kilgo PD, Weaver AA, Martin RS, Loftis KL, Meredith JW. Age thresholds for increased mortality of predominant crash induced thoracic injuries. Ann Adv Automot Med. 2010;54:41-50.

3. Brown SD, Walters MR. Patients with rib fractures: use of incentive spirometry volumes to guide care. J Trauma Nurs. 2012;19:89-91.

4. Baker SP, O'Neill B, Haddon W, Long WB. The injury severity score: a method for describing patients with multiple injuries and evaluating emergency care. J Trauma. 1974;14:187-96.

5. Garcia VF, Gotschall CS, Eichelberger MR, Bowman LM. Rib fractures in children: a marker of severe trauma. J Trauma. 1990;30:695-700.

6. Segers $P$, Van Schil $P$, Jorens $P$, Van Den Brande F. Thoracic trauma: an analysis of 187 patients. Acta Chir Belg. 2001;101:277-82.

7. Wilson RF, Murray C, Antonenko DR. Nonpenetrating thoracic injuries. Surg Clin North Am. 1977:57:17-36.

8. Ziegler DW, Agarwal NN. The morbidity and mortality of rib fractures. J Trauma. 1994:37:975-9.

9. Flagel BT, Luchette FA, Reed RL, Esposito TJ, Davis KA, Santaniello JM, et al. Half-a-dozen ribs: the breakpoint for mortality. Surgery. 2005;138:717-23.

10. Sharma O, Oswanski M, Jolly S, Lauer SK, Dressel R, Stombaugh HA. Perils of rib fractures. Am Surg. 2008:74:310-4.

11. Alexander JQ, Gutierrez CJ, Mariano MC, Vander Laan T, Gaspard DJ, Carpenter $\mathrm{CL}$, et al. Blunt chest trauma in the elderly patient: How cardiopulmonary disease affects outcome. Am Surg. 2000;66:854-7.

12. Bartlett RH, Brennan ML, Gazzaniga AB, Hanson EL. Studies on the pathogenesis and prevention of postoperative pulmonary complications Surg Gynecol Obstet. 1973;137:925-33.

13. Barnea $Y$, Kashtan $H$, Skornick $Y$, Werbin N. Isolated rib fractures in elderly patients: mortality and morbidity. Can J Surg. 2002;45:43-6.

14. Jones KM, Reed RL 2nd, Luchette FA. The ribs or not the ribs: which influences mortality. Am J Surg. 2011;202:598-604.

15. Legare C, Sawatzky JA. Dyspnea in the thoracic trauma patient: a human response to illness. J Trauma Nurs. 2010;17:36-42.
16. Dohi S, Gold MI. Comparison of two methods of postoperative respiratory care. Chest. 1978:73:592-5

17. Renault JA, Costa-Val R, Rossetti MB. Respiratory physiotherapy in the pulmonary dysfunction after cardiac surgery. Rev Bras Cir Cardiovasc. 2008;23:562-9.

18. Wilkins RL. Lung expansion therapy. In: Wilkins RL, Stoller JK, Kacmarek RM, editors. Egan's fundamentals of respiratory care. 9th ed. St. Louis: Mosby Elsevier; 2009.

19. Westwood K, Griffin M, Roberts K, Williams M, Yoong K, Digger T. Incentive Spirometer decreases respiratory complications following major abdominal surgery. Surgeon. 2007;5:339-42.

20. Agostini P, Naidu B, Cieslik H, Steyn R, Rajesh PB, Bishay E, et al. Effectiveness of incentive Spirometer in patients following thoracotomy and lung resection including those at high risk for developing pulmonary complications. Thorax. 2013;68:580-5.

21. Pasquina P, Tramer MR, Granier JM, Walder B. Respiratory physiotherapy to prevent pulmonary complications after abdominal surgery: a systematic review. Chest. 2006:130:1887-99.

22. Rollins KE, Aggarwal S, Fletcher A, Knight A, Rigg K, Williams AR, et al. Impact of early incentive spirometer in an enhanced recovery program after laparoscopic donor nephrectomy. Transplant Proc. 2013;45:1351-3.

23. Torgerson DJ, Roberts C. Randomisation methods: concealment. BMJ. 1999:319:375-6.

24. Ruppel G. Manual of Pulmonary Function Testing. 9th ed. St. Louis: Mosby; 2008.

25. Restrepo RD, Wettstein R, Wittnebel L, Tracy M. Incentive spirometry: 2011. Respir Care. 2011;56:1600-4.

26. Faul F, Erdfelder E, Lang AG, Buchner A. G*Power 3: a flexible statistical power analysis program for the social, behavioral, and biomedical sciences. Behav Res Methods. 2007;39:175-91.

27. Byun JH, Kim HY. Factors affecting pneumonia occurring to patients with multiple rib fractures. Korean J Thorac Cardiovasc Surg. 2013;46:130-4

28. Shulzhenko NO, Zens TJ, Beems MV, Jung HS, O'Rourke AP, Liepert AE, et al. Number of rib fractures thresholds independently predict worse outcomes in older patients with blunt trauma. Surgery. 2017;161:1083-9.

29. Ekpe EE, Eyo C. Effect of analgesia on the changes in respiratory parameters in blunt chest injury with multiple rib fractures. Ann Afr Med. 2017:16:120-6.

30. Ministry of Health and welfare, Taiwan. 2018 Taiwan health and welfare report. http://www.cdway.com.tw/gov/mhw2/book107/book1e/\#p=8. Published 2019.

31. Butts CA, Brady JJ 3rd, Whilhelm S, Castor L, Sherwood A, McCall A, et al. Do simple beside lung function tests predict morbidity after rib fractures. Am J Surg. 2017;213:473-7.

32. Chauny JM, Émond M, Plourde M, Guimont C, Le Sage N, Vanier L, et al. Patients with rib fractures do not develop delayed pneumonia: a prospective, multicenter cohort study of minor thoracic injury. Ann Emerg Med. 2012;60:726-31.

33. Renault JA, Costa-Val R, Rosseti MB, Houri NM. Comparison between deep breathing exercises and incentive spirometer after CABG surgery. Rev Bras Cir Cardiovasc. 2009:24:165-72.

34. Alaparthi GK, Augustine AJ, Anand R, Mahale A. Comparison of diaphragmatic breathing exercise, volume and flow incentive spirometer, on diaphragm excursion and pulmonary function in patients undergoing laparoscopic surgery: a randomized controlled trial. Minim Invasive Surg. 2016;2016:1967532.

35. Rollin KE, Aggarwal S, Fletcher A, Knight A, Rigg K, Williams AR, et al. Impact of early incentive spirometry in an enhanced recovery program after laparoscopic donor nephrectomy. Transplant Proc. 2013:45:1351-3.

36. Koo M, Hwang S. Comparison of effects of exhalation and inhalation breathing exercises on pulmonary function and complications in elderly patients with upper-abdominal surgery. J Korean Acad Nurs. 2016:46:514-22.

37. Moon D, Kim KH, Lee S. Effects of deep breathing with incentive spirometer on pulmonary function and $\mathrm{O}_{2}$ saturation by time process in patients with rib fracture. J Korea Contents Assoc. 2015:15:174-83.

38. Misthos P, Kakaris S, Sepsas E, Athanassiadi K, Skottis I. A prospective analysis of occult pneumothorax, delayed pneumothorax and delayed hemothorax after minor blunt thoracic trauma. Eur J Cardiothorac Surg. 2004;25:859-64.

39. Witt CE, Bulger EM. Comprehensive approach to the management of the patient with multiple rib fractures: a review and introduction of a bundled rib fracture management protocol. Trauma Surg Acute Care Open. 2017;2: e000064. https://doi.org/10.1136/tsaco-2016-00006. 
40. Brasel KJ, Moore EE, Albrecht RA, deMoya M, Schreiber M, Karmy-Jones R, et al. Western trauma association critical decisions in trauma: management of rib fractures. J Trauma Acute Care Surg. 2017:82:200-3.

41. Wartolowska K, Collins GS, Hopewell S, Judge A, Dean BJF, Rombach I, et al.

Feasibility of surgical randomised controlled trials with a placebo arm: a systematic review. BMJ Open. 2016;6:e010194.

\section{Publisher's Note}

Springer Nature remains neutral with regard to jurisdictional claims in published maps and institutional affiliations.

Ready to submit your research? Choose BMC and benefit from:

- fast, convenient online submission

- thorough peer review by experienced researchers in your field

- rapid publication on acceptance

- support for research data, including large and complex data types

- gold Open Access which fosters wider collaboration and increased citations

- maximum visibility for your research: over $100 \mathrm{M}$ website views per year

At BMC, research is always in progress.

Learn more biomedcentral.com/submissions 